\title{
Research on the Expression of Oil Painting Color on Contemporary Art Creation
}

\author{
Chunxia Wang
}

Hetao University, Bayannur, Inner Mongolia, 015000

Keywords: Oil Painting; color; art creation

\begin{abstract}
Contemporary oil painters have conducted many useful explorations on the horizontal expansion of color language. The statement paradigm of color language is unprecedentedly rich. The courage and results of this exploration are worthy of recognition. However, painters are still exploring the process of expanding the height and depth of color culture. The concept of modern color visual power needs to use the form of language. Therefore, "color visual power in painting" is an eternal task of conveying artistic spirit. In accordance with the laws of nature, artists face ubiquitous colors, although they are free to choose to re-create, but also reflect the traditional ability to deal with, escape, use, transform, and break all kinds of restrictions.
\end{abstract}

\section{Introduction}

Color is the most expressive and appealing artistic language in oil painting, and it is an important means for artists to express their inner experience and thoughts and emotions. The clever use of color plays a crucial role in the artistic expression of oil painting. In this regard, the author starts from the basic definition of color, analyzes the expression characteristics of color in contemporary oil paintings, and discusses the application of color in oil painting creation for reference.

\section{The Composition of Color Factors}

The composition of color factors includes emotions and spirits, and this is exactly the soul and core of the color representation. The main purpose of oil painting creation is to reproduce objective things through color factors. Therefore, to a large extent, the artist's subjective thinking is subject to objective facts. The expression of subjective emotions is the embodiment of the expressiveness of color factors. In a work, the artist's inner world and the true state of emotion are conveyed through the rich expression of color. This shows that the painter's subjective description of color is indispensable to break through the objective conditional limits of the material. Only in this way can he reach the subjective world of the painter with gray, color, light and dark contrasts, and exaggerated and strong transformations. Spiritual and emotional expression and expression. In the artist's subjective color language, it is emotion that comes first. The "objective" existence in the artist's eyes is no longer the "objective" world but the subjective world of "self". The perfect subjective world in the artist's eyes is to give his own consciousness to things that exist objectively. He will re-examine, position, re-assemble, and use his subjective will to reshape and sublimate the objective existence and become the cornerstone of his future creation. Once the artist has subjectively reconstructed and sublimated the objectively existing things, he will integrate more of his own inherent consciousness and thinking patterns into objective things. At this time, the objective world is strongly filled with the artist's Subjective ideology becomes a re-creation of objective things. This is why in paintings, why some people's mountains are green, and some people's mountains are red; some people's sun is yellow, and some people's sun is brown. Even if the same objective things are expressed, they have different psychological perceptions. That is because everyone has different emotional perceptions. Their transformation of the objective world is different. Therefore, the subjective world created is far from the same. 


\section{The Emotional Effect of Color Factors in the Expression of Oil Painting}

In appreciation of paintings, we can have a spiritual dialogue with the colors of the paintings because the colors in the paintings are almost all from the objective world of nature. The artist expresses himself with the colors extracted from the natural scene. Emotions, thereby affecting the emotions and behaviors of people viewing the works. Color, as an important factor in the oil painting creation process, is embodied in that it is not only an important expression technique in the painting art, but also an important bridge for emotion communication between the viewer and the painting. Color can directly affect people's emotions. It can not only make people excited, but also make people quiet. It can also bring joy or frustration to people [3]. This powerful expression shows that it is necessary to combine the expressiveness of color in painting with the artist's subjective emotional expression. Color allows artists to express their emotions and sublimate their thoughts. Painting works are an important way for artists to convey their emotions. Paintings contain a lot of emotional factors. Therefore, the expression of colors and the burst of spiritual emotions become paintings. The life of the work. The embodiment of the artist's own artistic personality is based on the perfect fusion of the picture and the spirit level. When the color and emotion are combined, the artist's subjective emotion cognition can be transformed into concrete painting works. In the process of creating oil paintings, because of the different subjectivity of each artist, the analysis and reorganization of the color and shape of the objective things are not the same. Therefore, the connotation, color, and shape of the works depicted by the artist are not Do the same. The depiction of color factors in a work embodies the different perceptions of the same thing by the artist and the different feelings of different things. This makes the artist's aesthetic taste and personality characteristics stand out in a straightforward manner in the artwork. Therefore, the expression of the artist's emotions in the works is depicted by colors. It can be seen that the emotional factors played by the color factors in the expression of oil paintings are quite large.

\section{The Role and Influence of Color Factors in the Creation Process of Artists}

In paintings, we can talk about colors because artists paint their own paintings using colors extracted from natural objects and natural scenes. Color can allow artists to express their emotions. Painting works are the way for artists to convey their emotions. Therefore, the expressive power of color becomes the life of paintings. Through the painting process to vent their emotions, it is the embodiment of the artist's own artistic personality in oil paintings. It is a perfect fusion of the image and the spirit. Everyone's subjective initiative is very different. Some people see the sky is gray, and some people see blue; Some people see sadness through the sea, because they are endless, while others see it. It is tolerance, it is also because it is endless. In the emotional perception of color factors, everyone has their own unique insights. Most of Van Gogh's works are dominated by yellow and orange. Yellow and orange give people passionate, unrestrained and passionate emotions. They are resonating with his distinctive personality that is close to madness and paranoia. He engaged in artistic creation with the will of the moths and the passion of fire. This crazy enthusiasm can only fully burn through yellow and red. His "Heilongjiang" writing style focuses on writing, expresses subjective enthusiasm, and gives people a sense of pursuit of light. In the later works such as "Starry Night" (Figure 6) and "Iris Flower" (Figure 5), he painted with wild, rough brushstrokes, and every brush stroke can make people feel his heart tremble. The fierce and unrestrained strokes, the lines twisting together, let people feel that the painter's heart is burning and crying. In oil painting creation, color is vitality. It is an important way for artists to reproduce the objective world and the subjective sensibility of people to the objective world through artistic means.

The realism of color emphasizes the pursuit of natural light and sense of reality. It is based on the principle of scientific color. Through the comprehensive application of the color of light source, intrinsic color, ambient color, and spatial color, it truly reproduces the shape of the objective object. Space, texture and other effects. In the creation of oil paintings, paying attention to the realism of color helps to create an immersive atmosphere that enhances the appeal of artistic images. For example, Luo Zhongli, a famous contemporary oil painter in China, used photographic realism in 
his oil painting "The Father," and successfully described it through subtle and detailed brushstrokes. Although he has experienced many vicissitudes of life, he is full of hope for life, optimistic and undying willpower. The simplicity, kindness, and honest image of the peasant father. The colors on the screen are realistic and delicate, saturated and thick, full and moist, dignified and touching, deep and rich in content, giving people a strong spiritual shock. Faces of loess, dry, black and thin face, ruts like wrinkles, gray beads of sweat on the brow, deep eyes, confusing eyes, clay in the nails, poorly worn tea bowls, these images are rich The rustic flavor reflects the author's respect and praise for the living workers. This kind of realistic expression means gives the work a powerful vitality, making the father's image more vivid, authentic and credible, flesh and blood, more likely to arouse people's inner emotional enthusiasm, ignite people's long-standing enthusiasm, touch people's heartstrings. When we gaze at this father's image in the sun, the significance of the work is no longer limited to the performance of the peasants but the symbol of the human soul.

The purpose of oil painting creation is to express emotions. Color is an important carrier of emotional ideas in oil painting creation. Different colors can express different emotional information and make people feel different inside. For example, red gives a warm, warm, intense, angry feeling; yellow gives a lively, lively, noble feeling; white gives a feeling of quietness, simplicity, innocence, innocence; black gives people dark, depression, gloomy, fear The sense; purple gives a mysterious, melancholy and quiet feeling. In the creation of oil paintings, the creative subjects have different personalities and different understandings of colors. The color choices used to express inner feelings will also be different. Therefore, the thoughts and feelings they express are different. For example, the Dutch post-impressionist Van Gogh likes to express his longing for life with brilliant yellow. In his work "Sunflower", yellow, light blue, and powerful brushstrokes show the dancing posture of the flowers and the fullness of the sunflower seeds. Texture, full of rhythm and vitality. At the same time, Van Gogh was more adept at expressing his inner world with a strong contrast of colors and expressing specific psychological emotions. Take the example of "Self-taping with a bandage on the ear and tie a pipe". In this self-portrait, he uses the contrast of the background red with the complement of the clothes and the green of the eyes, the orange on the upper part of the background, and the blue color of the hat. He was remorseful, distressed, and dull. For another example, Chinese realistic oil painter Wang Yidong is obsessed with using Chinese red to express his emotions and strengthen the expression of the theme. In his "Ancient Mountain Village", "Mengshan Morning Fog," "No. 2 in the House of Havoc", "Auspicious Smoke”, "Sunlight in the Winter", and the Yimeng Bridal Collection, all of them used red to express the festive and peaceful atmosphere of the picture .

\section{Conclusion}

The emotional role of color in paintings is increasingly valued by people. What ways and means does color play in paintings, highlighting their own expressiveness and enhancing their emotional power? Through different analysis and practice, I believe that the subjective color structure in the creation is an artist's overall synthesis of individuality and artistic accomplishment. In the creation of oil painting, it is necessary to strengthen the understanding, understanding, and use of color to make the color persuasive. And expressiveness. In the form of oil painting, the color factor is indispensable. The artist contrasts the color, controls the color tone, expresses the inner creative spirit and emotion, and makes the color become the soul of the oil painting.

\section{References}

[1] Dai Zhongwei. Reflections on the Decorative Color Language of Oil Painting [J]. Art Education Research, 2013(13).

[2] Xue Xinyu. Talking about Decorative Color Language in Oil Painting Creation [J]. Art Education Research, 2013(9).

[3] Sun Tiehong. On the aesthetic understanding of the hue formation in oil paintings[J].Studies of 
Fine Arts Education,2012(18).

[4] Li Wei. On the Color Expression in Oil Painting Art [J]. Music Grand View, 2012(6).

[5] Liu Xianbiao. Decoration in the Art of Gauguin[J].100 Artists,2010(S2). 